\title{
EL TRABAJO INMATERIAL EN EL CICLO MATERIAL DEL CAPITAL Y LA DETERMINACIÓN DE LAS CLASES SOCIALES EN EL CAPITALISMO CONTEMPORÁNEO
}

\author{
Adrián Sotelo Valencia*
}

\begin{abstract}
En el presente artículo, buscamos relacionar dialécticamente el concepto de trabajo inmaterial con el ciclo del trabajo material en la producción y reproducción del capital y de la sociedad burguesa. Asimismo, nos interesa reflexionar sobre algunas hipótesis en relación con la manera como lo anterior incide en la conformación de las clases sociales - y en sus luchas - en la sociedad capitalista contemporánea.

PAlabras Clave: Trabajo inmaterial. Clase y lucha social. Valor. Capitalismo.
\end{abstract}

El capitalismo es como un espejo que distorsiona los objetos esenciales

Difícilmente se puede ignorar que presenciamos un punto de inflexión en la historia contemporánea de la humanidad donde las antiguas condiciones y los paradigmas que habían regido la vida social de los hombres y las naciones están cambiando o se están agotando vertiginosamente. Algo similar a lo que ocurrió, guardando las correspondientes distancias y diferencias, entre la transición del viejo orden feudal al mundo capitalista en el curso de los siglos dieciocho y diecinueve. Sin embargo, y a diferencia de lo que piensan ciertos autores y corrientes de pensamiento, si bien constituye un cambio de época, de ninguna manera implica un cambio del modo de producción, ni de la formación social capitalista, ni de sus fundamentos esenciales como la propiedad privada de los medios de producción, la acumulación de capital y la explotación del trabajo, como efectivamente ocurrió en la mencio-

* Doutor em Estudios Latinoamericanos. Professor e investigador do Centro de Estudios Latinoamericanos (CELA) da FCPyS - UNAM. Coordenador do Programa Constitución Estructural de AL, UNAM.

Av. Universidad 1867-202, Col. Oxtopulco Universidad, Delegación Coyoacán, México D.F., CP. 04318. sotlova@hotmail.com nada transición histórica. Además, no se observa, por lo pronto, la existencia de aquéllas fuerzas y condiciones que Marx señala premonitoriamente en el Prólogo a la Contribución a la crítica de la economía política, y que citamos a continuación:

Ninguna formación social desaparece antes de
que se desarrollen todas las fuerzas productivas
que caben dentro de ella, y jamás aparecen
nuevas y más elevadas relaciones de producción
antes de que las condiciones materiales para su
existencia hayan madurado dentro de la propia
sociedad antigua. Por eso, la humanidad se
propone siempre únicamente los objetivos que
puede alcanzar, porque, mirando mejor, se en-
contrará siempre que estos objetivos sólo surgen
cuando ya se dan o, por lo menos, se están
gestando, las condiciones materiales para su
realización. A grandes rasgos, podemos designar
como otras tantas épocas de progreso en la
formación económica de la sociedad el modo de
producción asiático, el antiguo, el feudal y el
moderno burgués. Las relaciones burguesas de
producción son la última forma antagónica del
proceso social de producción [...]

Como vemos, Marx se refiere aquí a grandes épocas históricas, a períodos de mutaciones civilizatorias que involucran a los modos de 
producción y a las sociedades históricas que sobre ellos se erigen, y cuya dinámica de cambio societal implica, por término medio, décadas o siglos.

De esta cita podemos extraer dos tesis dialécticamente entrelazadas.

En primer lugar, la relación que guarda el desarrollo de las fuerzas productivas (materiales, sociales y humanas) con la antigua y nueva formación social en ciernes. Al respecto, es una ley social que se encarga de explicar la misma relación esencial y su proceso de gestación: la primera no puede perecer si en su seno no se han desarrollado todas esas fuerzas productivas, mientras que, para que emerja la nueva sociedad con su respectivo modo de producción -, es que en la antigua hayan madurado todas las condiciones y relaciones capaces de cohesionar el proceso con el fin de afianzar el cambio social y sus resultados.

La segunda tesis consiste en la posibilidad real - o no - de que las nuevas fuerzas sociales, políticas, culturales y militares sean capaces de estimular el cambio de un modo de producción y su sistema de relaciones sociales a otro nuevo que se proyecte al futuro y se consolide de manera duradera, es decir, que sea capaz de forjar su propio ciclo histórico.

Aplicando lo anterior a nuestra época contemporánea, considero que la primera tesis se cumple a cabalidad, es decir, las fuerzas productivas materiales lideradas por la revolución tecnológica, que surgió desde el período posterior a la segunda guerra mundial, han agotado sus potencialidades y se mantienen todavía dependientes, en sumo grado, de la energía eléctrica y del petróleo, a pesar del peso - por cierto, cada vez más importante-que en ella desempeña la revolución microelectrónica y su íntima imbricación con la información e internet (International Network).

El problema aquí es crítico: por un lado, determinar si, en los contornos del capitalismo, éste es todavía capaz de desplegar una segunda revolución industrial - o cuarta revolución científico-tecnológica - que estructure un nuevo ciclo productivo que impuse una nueva fase o etapa histórica del capitalismo como sucedió luego de la revolución industrial en Inglaterra. En este punto, me parece que hay que sopesar su relación con la producción de plusvalía y la potenciación del aumento de la tasa de ganancia en escala global, particularmente, en lo relativo a la tasa extraordinaria que es la que rige el sistema. Pero si lo anterior no ocurre, entonces, se puede concluir que todo impulso tecnológico y científico es superfluo para el capital. Esta tesis, que fue esbozada magistralmente por Marx en los Grundrisse, por su extrema importancia, la transcribimos in extenso:

Cuanto mayor sea el plusvalor del capital antes del aumento de la fuerza productiva, tanto mayor será la cantidad de plustrabajo o plusvalor presupuestos del capital, o tanto menor la fracción de la jornada de trabajo que constituye el equivalente del obrero, que expresa el trabajo necesario, y tanto menor el crecimiento del plusvalor recibido por el capital gracias al aumento de la fuerza productiva. Su plusvalor se eleva, pero en una proporción cada vez menor respecto al desarrollo de la fuerza productiva. Por consiguiente, cuanto más desarrollado sea ya el capital, cuanto más plustrabajo haya creado, tanto más formidablemente tendrá que desarrollar la fuerza productiva para valorizarse a sí mismo en ínfima proporción, vale decir, para agregar plusvalor, porque su barrera es siempre la proporción entre la fracción del día - que expresa el trabajo necesario - y la jornada entera de trabajo. Únicamente puede moverse dentro de este límite. Cuanto menor sea ya la fracción que corresponde al trabajo necesario, cuanto mayor sea el plustrabajo, tanto menos puede cualquier incremento de la fuerza productiva reducir considerablemente el trabajo necesario, ya que el denominador ha crecido enormemente. La autovalorización del capital se vuelve más difícil en la medida en que ya esté valorizado. El incremento de las fuerzas productivas llegaría a ser indiferente para el capital [...] Marx, K. (1980, p. 283-284).

Esta tesis de los Grundrisse es retomada y expuesta en El capital bajo la forma de ley:

Cuanto mayor sea la capacidad productiva del trabajo, tanto más corto será el tiempo de trabajo necesario para la producción de un artículo, tanto menor la cantidad de trabajo cristalizada en él y tanto más reducido su valor. Y por el contrario, cuanto menor sea la capacidad productiva del trabajo, tanto mayor será el tiempo de trabajo necesario para la producción de un artículo y tanto más grande el valor de éste. Por tanto, la magnitud de valor de una mercancía cambia en 
razón directa a la cantidad y en razón inversa a la capacidad productiva del trabajo que en ella se invierte Marx, K. (1980, p. 188).

De aquí la importancia de la tesis de Marx en relación con el desarrollo de las fuerzas productivas en función del progreso técnico, ya que constituye el núcleo duro de su teoría y opera con rango de ley en el sistema capitalista: "El incremento de las fuerzas productivas llegaría a ser indiferente para el capital”. ¿Qué significa esto?

Lo que tenemos al frente es que, por más que el capital revolucione sus medios de producción y de transporte, aplique la ciencia y la tecnología a los procesos productivos y de trabajo, con ello no consigue aumentar significativamente la producción de valor y de plusvalor (aunque si logre destruir la naturaleza y las fuerzas productivas de la sociedad); cuestión que coloca al sistema al borde de un peligroso camino de entrada en el (cuasi) estancamiento, en la recesión de largo plazo y en la barbarie depredadora, como parece estar ocurriendo hoy en día prácticamente en todo el mundo. ${ }^{1}$

El otro problema, se refiere a la segunda tesis, es decir, al hecho de determinar si, en la actualidad, en el contexto de la crisis global del capital, existen las fuerzas sociales y políticas suficientes y capaces no sólo de trastocar el régimen del capital y su modo de producción - lo que ya hacen algunos gobiernos desarrollistas y neo-estructuralistas que operan en la región andina de América Latina -, sino, además, de trascender el orden capitalista y constituir una nueva sociedad histórica diametralmente opuesta - y cualitativamente distinta y superior - al capitalismo. Al parecer esta última alternativa todavía no ocurre.

\section{AUTOVALORIZACIÓN DEL CAPITAL Y TRABAJO INMATERIAL}

Un ángulo desde el cual pueden verse las mutaciones ocurridas en los últimos años es el peso que va adquiriendo el trabajo intelectual,

${ }^{1}$ Mészáros, I. (2003). cognoscitivo e inmaterial en las determinaciones económicas y estructurales de la producción de valor. Dicho cambio ha servido para contrarrestar las limitaciones del tiempo de trabajo y la desmedida del valor, verdaderas causas de la crisis del capitalismo contemporáneo, que se ramifican en los sistemas inmobiliarios y financieros del capital ficticio, que es justamente el que hoy está en crisis.

Sostenemos la tesis de que el trabajo intelectual es parte de la humanidad de la fuerza de trabajo del obrero, que le es arrebatado por el capital para emplearlo como medio de producción de valor y plusvalor; convirtiéndolo, además, en un mecanismo petrificado en la máquina y en la tecnología, con lo que se refuerza el fenómeno de extrañamiento y del control gerencial del obrero por el proceso de trabajo y la gerencia.

El problema esencial radica, a nuestro juicio, en el hecho de que la actual crisis capitalista del mundo es esencialmente una crisis de producción de valor y de plusvalor, idea que derivamos de los planteamientos que Marx desarrolló en los Grundrisse y, posteriormente, en El $_{\text {capital }}{ }^{2}$ y que exponemos en un libro como tesis central. ${ }^{3}$

Se trata de concebir el capitalismo actual como una fase caracterizada fundamentalmente por crecientes dificultades que se presentan en la producción de valor y de plusvalor y, por ende, en la manera cómo inciden constantemente en los procesos de acumulación y reproducción del capital y en la formación de las tasas de ganancia (media y extraordinaria). A partir de ahora, es preciso relacionar estas últimas con la dinámica del capital ficticio que, por cierto, es hegemónico dentro del ciclo del capital.

El tiempo de trabajo - promedio, exacto, social y necesario - disminuye, pero lo hace cada vez menos, marginalmente, debido, entre otros factores: a) al desplazamiento de fuerza de trabajo,

2 Vale la pena comentar que consideramos ambas obras como una secuencia complementaria, epistemológica y conceptual, y no, como plantea Antonio Negri en su Marx más allá de Marx, como obras separadas (la primera por encima de la segunda), ni como en el planteamiento de Louis Althusser de la fragmentación generacional y la "ruptura epistemológica", en la que divide el pensamiento de Marx como si fueran rebanadas ideológicas.

${ }^{3}$ Sotelo Valencia, A. (2010) 
que provoca el aumento de la composición orgánica del capital (la relación entre capital constante (medios de producción y materias primas) y capital variable (la fuerza de trabajo); b) al desarrollo tecnológico que, en sí, no crea valor ni, por ende, plusvalor, sino que sólo lo transfiere al producto final, contrariamente a lo que sostiene las tesis posmodernistas y evolucionistas; finalmente, c) a la constante producción de plusvalor relativo articulada con la producción de plusvalor absoluto y a la superexplotación de la fuerza de trabajo. Adicionalmente, la crisis, derivada de las crecientes dificultades del capital para reducir la magnitud del tiempo de trabajo lo suficiente como para aumentar la tasa de plusvalor, intensifica el proceso de liofilización organizacional, traducida en: a) reducción del trabajo vivo, b) aumento del trabajo muerto, c) sustitución del trabajo manual por el dispositivo técnico-científico, d) mayor apropiación de la subjetividad obrera y, d) diseminación de la precariedad del trabajo y de las empresas terciarias (outsourcing) por toda la sociedad (Antunes, R. 2005, p. 233-234).

De lo anterior derivamos la siguiente hipótesis: por más que siga aumentando la productividad, desarrollándose la revolución tecnológica y ahorrado fuerza de trabajo mediante el aumento del ejército industrial de reserva - como por cierto está ocurriendo como consecuencia de la actual crisis mundial del modo de producción capitalista -, la reducción del tiempo de trabajo socialmente necesario para la producción de mercancías y de fuerza de trabajo va perdiendo funcionalidad y se va volviendo marginal, es decir, cada vez más insignificante como medio para producir valor y plusvalor, aunque progresivamente esté aumentando, en la sociedad, el volumen general de la riqueza física (valores de uso). Entonces, el sistema entra en crisis orgánica, estructural y civilizatoria.

Al respecto, Giovanni Alves apunta certeramente que:

El crecimiento de la productividad del trabajo en las últimas décadas, debido a las innovaciones tecnológico-organizacionales del capital, significó una tendencia a la disminución relativa del trabajo vivo en la producción social, dentro de un orden mercantil dominado por una acumulación crecientemente financiera que preserva la obligación de trabajar (Alves, G. 2011, p. 24-25).

El desdoblamiento de la acumulación de capital y su concentración en la esfera financiera se vuelven, entonces, una urgente e imperante necesidad del capital social global para seguir existiendo, aún a costa de constreñir la producción de plusvalor y presionar al sistema hacia un proceso de cuasi-estancamiento económico como está ocurriendo hoy en día en la economía capitalista mundial y en sus principales regiones socioeconómicas como la Unión Europea, Asia, Estados Unidos y América Latina.

A nuestro juicio, y desde el punto de vista de la lucha de clases, la salida del sistema se desdobla en dos vertientes. Por un lado, en la tendencia creciente a apropiarse del trabajo subjetivo del obrero colectivo en su conjunto para convertir y materializar dicha subjetividad en producción de plusvalor. Por otro lado, en una fuerte tendencia, que incluso se propaga en los países del capitalismo avanzado y en sus procesos productivos de trabajo, a superexplotar la fuerza de trabajo, es decir, a expropiar parte o una proporción importante de su fondo de consumo para convertirlo en una fuente adicional de la acumulación, lo que redunda en un aumento de la tasa de plusvalor y de la ganancia favorable al capital. Ambos procedimientos constituyen piezas maestras de la nueva organización científica e informacional del trabajo, generalmente articuladas en el conocido sistema de origen japonés llamado toyotismo. ${ }^{4}$

Esta concepción de la subjetividad vinculada al trabajo inmaterial no puede siquiera sostenerse si no se considera que dicho trabajo corresponde, en términos generales, al funcionamiento del ciclo de la producción y del trabajo material en el capitalismo contemporáneo.

${ }^{4}$ Para el tema de la extensión de la superexplotación del trabajo al mundo desarrollado, véase: Ruy Mauro, Marini, "Proceso y tendencias de la globalización capitalista", en: Marini, R.; Millán, M. (1996, p.49-68. v.4). Hay versión en internet: http://biblioteca.clacso.edu.ar/ar/ libros/secret/critico/marini/08proceso. pdf. 
Cuando se habla de trabajo inmaterial, cognoscitivo, intelectual, subjetivo - términos que hoy están de moda en las fronteras del arte de las ciencias sociales - pareciera que se está aludiendo a cambios esenciales, ontológicos, en el modo de producción, de vida y de trabajo que-supuestamente - habrían hecho "anacrónicos" los términos de Marx: trabajo concreto, trabajo abstracto, valortrabajo, plusvalor, capital productivoimproductivo, etcétera. Es decir, que se habría cambiado completamente la naturaleza del modo de producción capitalista por otra cosa. Pero nada más alejado de esto. Por el contrario, lo que tenemos es una articulación virtuosa entre el trabajo material y el trabajo inmaterial concebidos como unidad dialéctica que opera a través de la información, la ciencia y la tecnología como principales fuerzas productivas.

En términos sintéticos, esto significa que las tecnologías de información y comunicación lograron suprimir virtualmente las limitaciones físicas del tiempo de trabajo a través de lo que denominamos ciberespacio; consiguieron reducir infinitamente los tiempos muertos de la producción y la porosidad de las jornadas de trabajo en todo el mundo con la intermediación del sistema de máquinas computarizadas. Pero ni así consiguió el sistema la estabilidad estructural de la economía, ni tasas crecientes de desarrollo económico que impidieran el advenimiento de la crisis y sus secuelas. Un autor reconoce que

La plusvalía generada por el trabajador colectivo de las telecomunicaciones es una plusvalía en tiempo real y virtual. Un plusvalor que se genera y realiza en red en todo el planeta al que es capaz de comunicar socialmente. Una llamada de teléfono, la conexión a Internet o el triple play crean plusvalía en tiempo real y virtual en el proceso de interconexión de los discursos, de los símbolos, en el almacenamiento y en el procesamiento de voz, de información y de imágenes (Trejo, R. 2012, p. 337).

La apropiación de la subjetividad humana y la intensificación de los ritmos de producción tienen un límite histórico-estructural que ni siquiera la revolución tecnológica ha podido su- perar. Por ello, en los intersticios de esta crisis, el capital tendrá que desencadenar - y es muy factible que fracase-una nueva revolución técnico-científica y desplegar una serie de políticas y estrategias articuladas que coadyuven a su superación, de tal manera que se pudiera generar un nuevo ciclo de desarrollo capitalista vinculado con la producción de plusvalor. Pero esta última salida es extremadamente difícil, más aún, si en el futuro se presenta obstaculizada por el surgimiento de un nuevo sujeto revolucionario en cuyo núcleo se encuentren la clase obrera y los proyectos políticos de superación del orden capitalista. Así, nuevamente, la lucha entre el trabajo y el capital se presenta como la partera de la historia.

Autores como Giovanni Alves observan que lo que en el sistema existe es el proceso de trabajo capitalista que involucra diversas formas de trabajo, entre las que se encuentra el material y el inmaterial y refutan la existencia de un "ciclo" de trabajo exclusivamente inmaterial:

[...] es un equívoco el concepto de 'proceso (o ciclo) de la producción inmaterial'. En verdad lo que existe es proceso de trabajo capitalista, un complejo vivo de trabajo que articula, en sí, trabajo material y trabajo inmaterial. Constituye una fantasía conceptual admitir un tipo puro de trabajo inmaterial, al igual que la disyunción trabajo material/trabajo inmaterial (Alves, G. 2006, p. 70).

Además, como plantea el autor, hay que enfatizar que, como producto del trabajo colectivo, el trabajo inmaterial es expresión genuina y contradictoria del trabajo abstracto (que determina la formación del valor y del plusvalor) y reafirma la existencia del trabajo material que despliega la fuerza de trabajo colectiva. ${ }^{5}$

Si consideramos que la "subjetividad" corresponde al ámbito del trabajo inmaterial y que éste es una forma infinitamente más desarrollada del trabajo material, cuya reproducción depende del proceso de explotación capitalista, entonces resulta completamente falsa la tesis de los autores, que supone la "autonomía" del trabajo inmaterial

${ }^{5}$ Para este tema véase el libro de Karl Marx (1981). 
y su reproducción en la exclusiva esfera de la subjetividad humana. Esta, en verdad, es apropiada por el capital y, en última instancia, subsumida a la producción de valor y entra, por tanto, en la lógica de la reproducción del capital y de sus leyes esenciales.

La categoría "desmedida del valor" se desprende de la tendencia del capital a convertir el trabajo en trabajo inmaterial y, de este modo, éste último a operar como su causa (Alves, G. (2009, p. 33). Pero aquí es importante señalar que, a diferencia de otros autores como André Gorz, Lazzarato y Negri, el trabajo inmaterial, para nosotros, está indisolublemente ligado al ciclo del trabajo material y se explica por él; por tanto, validando la ley del valor-trabajo y su correspondiente teoría al comprenderlo dentro de sus dimensiones ontológicas y categoriales fundamentales. ${ }^{6}$

Por otro lado, el trabajo inmaterial, al igual que el material, también está sujeto a las contradicciones esenciales del capitalismo y a los procesos y tendencias que apuntan a deshabilitar el "tiempo de trabajo" - que había sido el eje alrededor del cual se calculaban los valores y precios de producción de las mercancías -, al influjo de lo que anteriormente denominamos desmedida del valor, que provoca, primero, que el tiempo de trabajo entre en estado de tensión y, más tarde, en una crisis que genera nuevos problemas para la reproducción del capital a partir de ganancias, ya que estas categorías dependen del límite del tiempo de trabajo donde, como dice Marx, "Los átomos del tiempo son los elementos creadores de la ganancia” (Marx, K. 2000, p. 188).

Si bien es un hecho histórico la tendencia del capital a prescindir de la fuerza de trabajo en sus procesos materiales e inmateriales de producción y reproducción de mercancías, sin embargo, no puede hacerlo del todo, ya que estaría lesionando y liquidando sus propias bases económicas, sociales y materiales de reproducción. En efecto, como expresa Amorim: “[...] históricamente el capital tiende a limitar y reducir

Al respecto véase nuestro libro: Sotelo Valencia (2012).

su dependencia en relación al trabajo, pero no puede hacerlo por completo, pues depende de su explotación para generar plusvalor" (Amorim, $\mathrm{H}$. 2009, p. 17-18).

En este contexto, el problema del analista simbólico del capital (Reich, R. 1993) (que, para algunos autores, representa al trabajo inmaterial) consiste en lograr incrementar la tasa de explotación del trabajo (la relación entre el tiempo de trabajo socialmente necesario y el trabajo excedente no remunerado), que es la relación determinante de la formación del plusvalor.

$\mathrm{Al}$ respecto, cabe recordar que el tiempo de trabajo socialmente necesario se determina por el desarrollo de las fuerzas productivas y por el grado medio de destreza, productividad e intensidad de la fuerza de trabajo que actúan como procesos interrelacionados (Marini, R. 1978, p. 64).

La producción del nuevo valor (el equivalente de la fuerza de trabajo más la plusvalía), así como la conservación y la transferencia del valor de los medios de producción, corre a cargo exclusivamente de la fuerza de trabajo al amparo de su doble carácter de ser productora de valor. Y el método más idóneo que encuentra el capital, es producir plusvalor relativo con cargo en la explotación de la fuerza de trabajo y en el incremento de la productividad, la cual, en el largo plazo, entra en contradicción con las necesidades inmanentes de valorización del capital y del incremento de la tasa de ganancia, que son vitales para afianzar la reproducción ampliada del sistema.

En la actualidad, estas dos contradicciones se han potenciado con el desarrollo científico y tecnológico. Pero, al hacerlo, han puesto en jaque la producción de valor y de plusvalor por lo quedebido tanto a que el sistema sigue reposando en el modo de producción capitalista y en sus conceptos y categorías fundamentales: explotación, propiedad privada, apropiación mercantil, valorización, monopolio, así como en la lógica del metabolismo social del capital - resulta necesario extender la superexplotación del trabajo como un proceso universal que se impone para mantener la continuidad de la reproducción del valor y del 
régimen de producción de mercancías, encaminado a la producción de plusvalor y de ganancias incrementadas. ${ }^{7}$

\section{TRABAJO INMATERIAL, VALORIZACIÓN DEL CAPITAL Y LUCHA DE CLASES}

La existencia del trabajo y del capital como antípodas de la sociedad capitalista no es un capricho de la historia ni una fatalidad indefinible, ni mucho menos una ilusión de intelectuales trasnochados. Es, eso sí, una realidad existente que se nutre día a día dentro del metabolismo necesario y reproductivo de la sociedad capitalista estructurada en clases sociales y en la existencia de la propiedad privada como su principio constitutivo que la regula. El trabajo abstracto - responsable de la substitución del trabajo concreto y su conversión en mercancía - no puede desaparecer por más que, como dijimos, su morfología haya experimentado evidentes modificaciones a partir del último cuarto del siglo XX. Esos cambios efectivamente se han expresado en una complejificación y ramificación de las relaciones sociales, al lado de evidentes procesos de urbanización acelerada y del surgimiento denuevos sectores de valorización de capital (nuevas tecnologías, capital ficticio, call centers, etcétera). en esferas como telecomunicaciones, informática, telemática, microelectrónica, marketing y deformas postayloristas y postfordistas de organización del trabajo, como el toyotismo, conectadas con los procesos de producción y de valorización del capital.

La existencia del capital social global, con su red de aparatos e instituciones, revela que él es un producto del trabajo (muerto), pretérito, cuya reproducción y mantenimiento obedece al trabajo vivo cualquiera que sea la forma que éste asuma. Puesto que aquí lo que cuenta no es tanto el "trabajador individual", el "trabajador concreto" (minero, albañil, metalúrgico, técnico o programador) y la actividad particular que despliegue (en

${ }^{7}$ Este tema lo desarrollo en mi libro: Crisis capitalista y desmedida del valor..., op. cit. Véase también Ruy Mauro Marini, "Proceso y tendencias de la globalización capitalista”, op. cit. tanto valor de uso), sino el trabajador social global que articula - y sintetiza - a los trabajadores productivos e improductivos de la sociedad que le son necesarios al capital para concurrir a su autovalorización con el objetivo de producir plusvalor y elevar la tasa de ganancia.

De esta manera, los cambios que operan en la base de la sociedad capitalista, es decir, en las relaciones sociales de producción y en el aumento inusitado de la productividad del trabajo, no dejan intocadas a las clases sociales que constituyen y reproducen a la sociedad burguesa. Sin embargo, al mismo tiempo, ésta no se extingue al influjo de las transformaciones que produce el surgimiento de nuevos procesos de acumulación y reproducción del capital cimentados en el trabajo inmaterial y cuyo ciclo, como vimos, aún reposa y se explica - en función del ciclo del trabajo material, el cual, a la par, depende de la ley del valortrabajo y de sus categorías esenciales: explotación, plusvalía, tasa de ganancia (media y extraordinaria), propiedad privada de los medios de producción y de consumo, reproducción ampliada y crisis estructurales y sistémicas provocadas, esencialmente, por los problemas que se presentan en la producción del valor y del plusvalor derivados de la crisis del trabajo abstracto.

$\mathrm{Al}$ respecto, como dice Alain Bihr:

En el fondo lo que se expresa de esta manera es una contradicción entre el valor de uso (trabajo concreto) y el valor de cambio (trabajo abstracto), ya que '...la producción misma de trabajo abstracto implica que absorbe tendencialmente cada vez menos trabajo vivo por unidad de trabajo muerto. Es lo que produce la baja tendencial de la tasa media de ganancia, en perjuicio de los aumentos de productividad que constituyen la principal contratendencia interna a dicha ley. Con lo que se socava la base misma de la formación de valor (Bihr ,A. 2010, p. 37).

Sin embargo, por otro lado, tampoco podemos sostener que la estructura de clases y sus luchas en diversos planos - económicas, sociales, políticas e ideológicas - no hayan experimentado cambio alguno; sería una negación insostenible, al mismo tiempo que inverosímil hacerlo. Más bien, 
a nuestro juicio, podemos indicar los siguientes cambios que han ocurrido a partir de las constantes reestructuraciones operadas por el mundo del trabajo y por el mismo capital en las últimas tres décadas y que se han proyectado tanto en la estructura de las clases sociales como en sus diversas manifestaciones. Al final, reflexionaremos sobre los probables impactos que, en particular, ha acarreado el trabajo inmaterial en los procesos clasistas y sus proyecciones conflictivas.

En primer lugar, consideramos que las clases sociales - cualquiera que sea su definición ${ }^{8}$ - se han diversificado y complejizado en función de los procesos de reproducción del capital que han traído consigo, al lado de la gran industria, nuevos procesos de trabajo y formas de organización laboral que alteraron perfiles y comportamientos de clase y de fracciones de clase, calificación obrera, escalas y jerarquía salariales, categorías y funciones desempeñadas. También en el plano estructural de las clases dominantes, en virtud de los problemas de la valorización del capital, junto a la contracción de las tasas promedio de crecimiento del capitalismo contemporáneo, han surgido nuevas clases y fracciones de clase hegemonizadas por lo que Marx llamaba capital ficticio, que hoy se expresa predominantemente en la hegemonía que poseen las empresas trasnacionales, los empresarios financieros y los organismos supranacionales, como el Fondo Monetario Internacional y el Banco Mundial, que representan los

${ }^{8}$ Dentro del marxismo se pueden citar las siguientes obras que contienen elementos para construir una definición contemporánea de las clases sociales. De Marx: Carta a Weyde-meyer, El Capital, Cap. III; El Dieciocho Brumario de Luis Bonaparte, La Guerra Civil en Francia, Las luchas de clases en Francia, El Manifiesto del Partido Comunista, La Miseria de la Filosofía; de Engels, Las guerras campesinas en Alemania; de Lenin, Una gran iniciativa, El desarrollo del capitalismo en Rusia, El imperialismo: fase superior del capitalismo, ¿Quié-nes son los amigos del pueblo?, El Estado y la revolución, El programa agrario de la socialdemocracia rusa, El partido obrero y el campesinado, etc. También las obras de Poulantzas son fundamentales tanto en la sistematización de las obras clásicas como en el aporte de nuevos elementos: Poder político y clases sociales en el Estado capitalista, Siglo XXI, México, 1971 y Las clases sociales en el capitalismo actual, Siglo XXI. México, 1978. En la óptica funcionalista, por lo menos son importantes las siguietes obras: Stanislav Ossowsky (1969), Georges Gurvitch (1973). Una mirada de conjunto de esta corriente en lo relativo a las clases sociales figura en Nicole LaurinFrenette (1985). intereses parasitarios de las clases dominantes más retardatarias de la sociedad mundial capitalista.

En segundo lugar, junto a una relativa disminución del contingente de obreros industriales directamente relacionados con la transformación material de la naturaleza y la producción de plusvalor, han surgido nuevos contingentes de la clase trabajadora que operan en los sectores de servicios y en el llamado "sector del conocimiento" - por cierto aún restringido en escala mundial por más que el posmodernismo lo pondera como hegemónico -, donde se aglomeran técnicos, ingenieros y personal calificado y semicalificado, que configura la categoría socioeconómica y sociotécnica del infoproletariado, es decir, de todo un sector de trabajadores directamente ligados a las actividades productivas y mercantiles de la información, precarios, polivalentes y flexibles (Antunes, R.; Braga, R. 2009).

Por último, reflexionemos sobre la relación entre trabajo inmaterial, clases sociales y lucha de clases que, por cierto, sigue existiendo como antípoda y motor del desarrollo histórico del modo de producción capitalista y su formación económico-social.

En el capitalismo histórico, es decir, desde el siglo XVI hasta la actualidad, las tres clases sociales principales de la sociedad burguesa se derivan de las tres fuentes económicas fundamentales: el salario (obreros asalariados), la ganancia (capitalistas) y la renta de la tierra (terratenientes), que además constituyen la base de su "identidad de clase": "Se trata de tres grandes grupos sociales, cuyos componentes, los individuos que los forman, viven respectivamente de un salario, de la ganancia o de la renta del suelo, es decir, de la explotación de su fuerza de trabajo, de su capital o de su propiedad territorial" (Marx, K. 2000, p.817). Y son estas fuentes materiales las que definen tanto a las clases sociales fundamentales (burguesía y proletariado) como a las principales (burguesía, proletariado, clases medias, terratenientes, campesinos), y de allí es posible desprender otros componentes sociales tales como fracciones de clases, grupos, estamentos, castas, etcétera, pero que se derivan 
siempre de las categorías fundamentales de la reproducción material.

Para Marx una clase social existe: "En la medida en que millones de familias viven bajo condiciones económicas de existencia que las distinguen por su modo de vivir, por sus intereses y por su cultura de otras clases y las oponen a éstas de un modo hostil” (Marx, K. s.f, p. 171).

Por su parte, Lenin define las clases sociales como:

Grandes grupos de hombres que se diferencian entre sí por el lugar que ocupan en un sistema de producción social históricamente determinado, por las relaciones en que se encuentran con respecto a los medios de producción (relaciones que las leyes refrendan y formulan en su mayor parte), por el papel que desempeñan en la organización social del trabajo y, consiguientemente, por el modo y la proporción en que perciben la parte de riqueza social de que disponen. Las clases son grupos humanos, uno de los cuales puede apropiarse del trabajo del otro por ocupar puestos diferentes en un régimen de economía social (Lenin, V.I. 1971, p. 504).

Para no inducir a equívocos, hay que enfatizar que este primer nivel genético-estructural de definición de las clases sociales debe contemplar los constituyentes sociales, jurídico-políticos y la formación de la conciencia ideológica que intervienen en su conformación y en la estructuración de las sociedades de clase. No existe, por tanto, una relación mecánica e inmediata entre situación estructural de las clases y conciencia social y política de clase, porque ésta se ve influida y mediada por la ideología dominante y por las instituciones de persuasión del poder político, como los medios de comunicación, la iglesia y la escuela. Por esa razón, Agustín Cueva, que indica la necesidad de formular una definición amplia de clase social, dice: "El marxismo sostiene que el problema de las clases sociales no puede estudiarse correctamente si no es a partir de una teoría general de la sociedad y de la historia" (Cueva, A. 1987, p. 8). Y en efecto, como bien dice este autor, las clases sociales, en tanto agregados humanos vinculados por intereses materiales, sociales, culturales y espirituales comunes, no pueden concebirse en sí mismas al margen de la estructura histórico-social y del modo de producción, sino que deben entenderse dentro del conjunto de determinaciones e instituciones de la sociedad de la que forman parte, como el Estado, que le imprimen su dinámica. De tal manera que una clase social como los indígenas, por ejemplo, en situaciones histórico-sociales concretas determinadas, puede mantener posiciones de avanzada dentro de las luchas sociales, o bien, aparecer aliada con las posiciones retardatarias y conservadoras de las clases superiores de la oligarquía, aunque los primeros formen parte del proletariado en sentido amplio. Pero, en general, se debe distinguir la clase - en tanto concepto teórico - de su expresión empírica, que se puede apreciar en la cotidianeidad y en la dinámica de los movimientos sociales. De esta forma, por ejemplo, las insurrecciones del trabajo que todos los días registra la prensa internacional de todo el planeta plantean la interrogante: ¿quiénes son los insurrectos? La respuesta es: miles y miles de trabajadores manuales, intelectuales, técnicos y administrativos; campesinos sin tierra, obreros agrícolas, estudiantes, hijos de trabajadores, proletarios de las ciudades y del campo, profesores de enseñanza primaria y secundaria. Categorías vinculadas tanto a la industria y la agricultura como a los sectores más "invisibles" de las telecomunicaciones, los servicios y las industrias del "conocimiento y del software". Pero, en muchas ocasiones, los bastiones de la clase obrera industrial (tradicional y moderna) no aparecen en la escena de las luchas o, por lo menos, en las primeras filas de las batallas antiestatales y contra el capital, y esta "ausencia" ha nutrido tanto las teorías del fin del trabajo como las de los "nuevos movimientos sociales" que, supuestamente, habrían "sustituido al proletariado" y a la clase obrera como sujetos históricos de la transformación social, por lo menos en el sentido en que Marx lo planteó. Pero el hecho es que estos movimientos, como bien dice Mészáros (Mészáros, I. 2001, p. 46-47) “[...] pueden ser marginados y separados uno por uno, dado que no pueden pretender representar una alternativa coherente y comprehensiva al orden establecido 
como modo de control metabólico social y sistema de reproducción social”. Sólo el trabajo es capaz, incluso en nuestros días, de proporcionar un marco estratégico global que integre a todos los movimientos anticapitalistas y emancipatorios dentro de un proyecto alternativo y de superación del sistema capitalista.

Que muchos movimientos sociales estén compuestos de campesinos, indígenas y maestros - que, por ejemplo, en México han sido y son protagonistas de vanguardia - junto con otros sectores de la clase trabajadora, como los electricistas y los tranviarios, por no mencionar a otros sectores de trabajadores rurales que han protagonizado verdaderas campañas de lucha por la defensa de sus intereses de clase, no indica que no sean movimientos proletarios y entrelazados de alguna manera con el "mundo del trabajo". De la misma forma, en otras coyunturas de intensa lucha política y social, mineros, astilleros o trabajadores automotrices destacan en las movilizaciones, en las huelgas y en las apropiaciones de fábricas e instalaciones, así como en los cortes de ruta como mecanismos de presión contra el capital y el Estado por la mejora de sus condiciones salariales, de vida y de trabajo en América Latina y Europa Occidental.

Un proyecto de transformación social, en estas condiciones, no pude ser obra exclusiva del proletariado industrial - que, en el mundo actual, tiende a disminuir por las mutaciones operadas tanto en las estructuras de acumulación y reproducción del capital como en las de las clases sociales -, sino de todas las clases explotadas de la sociedad burguesa y neoliberal de nuestros días, aunque, eso sí, con la clase obrera industrial (tradicional y moderna) como núcleo central, en alianza con los diversos movimientos sociales con los que se pueda avanzar. Así, en los últimos años, los trabajadores se han insurreccionado contra la política patronal de la Unión Europea, como en las jornadas de lucha de los mineros españoles del carbón y de los astilleros; en las huelgas y movilizaciones, en Barcelona, de los trabajadores indocumentados de origen ecuatoriano y dominicano contra los bajos salarios, la temporalidad laboral y las extenuantes jornadas de trabajo; en el movimiento de los trabajadores y estudiantes de Francia que, juntos, echaron abajo el Contrato de Primer Empleo (CPE), que significaba legalizar la superexplotación y la precariedad del trabajo no sólo en ese país sino en los otros afiliados a la Unión Europea.

Por ejemplo, a propuesta de Inglaterra, los 27 ministros de los países miembros del bloque comunitario (Unión Europea) que cuentan con "mayoría calificada" aprobaron un acuerdo que aumentaba la jornada de trabajo hasta 65 horas (y que fue ratificado el 9 de junio de 2008 por el Consejo Europeo de Ministros de Estado), en un vergonzoso acto de imposición a los trabajadores europeos, cuestión que estimuló las luchas obreras en esa región, al grado de que forzaron al Parlamento Europeo, reunido en Estrasburgo, Francia, a rechazar ese proyecto de ley antiobrera el 17 de diciembre de 2008. ${ }^{9}$ Habrá que ver si la patronal europea arremete nuevamente presionando a los gobiernos y los sindicatos. Mientras tanto, de aprobarse en el futuro, esa política de aumento de la jornada laboral (plusvalía absoluta) tendría graves repercusiones para los trabajadores de Asia, África y América Latina, donde en algunos países como Chile, la jornada de trabajo efectiva sobrepasa las 14 horas por día. ${ }^{10}$

El aumento de la jornada de trabajo en Europa provocaría, en otras regiones, el aumento del tiempo de trabajo promedio, la reducción de los

${ }^{9} \mathrm{Al}$ respecto, véase: LA UNIÓN Europea acuerda ampliar la jornada laboral hasta un máximo de 65 horas semanales. Rebelión y RECHAZÓ el Parlamento Europeo proyecto de ley para aumentar la jornada laboral, Lajornada, 18 dic. 2008.

${ }^{10}$ Desde 1996, "Chile es miembro de los 10 países del mundo que más horas trabaja a la semana, pese a la rebaja legal de 48 a 45 horas de trabajo semanales. En realidad, la jornada laboral llega a 14 horas diarias, considerando transporte y tiempos muertos. En nuestro país, se trabaja un $25 \%$ más que en los países desarrollados con los que se mantienen tratados comerciales. Así y todo, estamos en el $40 \%$ más bajo de los niveles de productividad mundial”. Declaración de María Ester Féres, académica de la Universidad Central de Chile y ex directora del Ministerio del Trabajo, en: Andrés Figueroa Cornejo, "Reflexión acerca de las luchas de los trabajadores bancarios contra la flexibilidad laboral", rebelión, http://www.rebelion.org/noticia.php?id=56948 20 sep. 2007. 
salarios reales y la intensificación del trabajo. Estas medidas constituyen intentos de solución a la crisis del tiempo de trabajo y a la desmedida de valor.

Volviendo a El capital, consideramos que, de una lectura articulada de sus tres tomos, puede desprenderse que el sujeto asalariado, que vende su fuerza de trabajo (manual y cognoscitiva) y es explotado por el capital, que transforma la naturaleza, que produce medios de producción y de consumo, y que crea el plusvalor que aumenta la acumulación de capital definitivamente pertenece a la clase obrera.

En el Manifiesto del partido comunista podemos ver que esa misma clase obrera industrial constituye también el núcleo duro del proletariado - en el sentido amplio que Marx y Engels le atribuyen en este texto -, formado por los desprendimientos y pauperizaciones de todas las clases sociales de la sociedad burguesa. Se le denomina, en esta obra, "clase explotada y oprimida": "el proletariado, esa clase obrera moderna [...] se recluta de entre todas las clases de la población" (Marx, K.; Engels, F. s.f., p. 39).

Para otros autores proletariado es sinónimo de clase de los trabajadores asalariados, clase social de los vendedores de fuerza de trabajo (Alves, G. 2007. p. 97), que componen la totalidad viva del trabajo; objeto de explotación, expoliación y expropiación del capital, que se inserta en una multiplicidad de actividades que van desde la producción, la circulación y el consumo de mercancías, incluso, hasta la administración pública (Alves, G. 2007. p. 97).

Antunes también utiliza como sinónimos:"proletariado", "clase trabajadora", "clase que vive del trabajo", como se puede apreciar en el siguiente pasaje:

Yo diría, entonces, para comenzar a hacer un bosquejo de esta problemática, que el proletariado o la clase trabajadora hoy (la que denominé como clase-que-vive-del-trabajo) comprende a la totalidad de los asalariados, hombres y mujeres que viven de la venta de su fuerza de trabajo y que están desposeídos de los medios de producción. Esta definición marxiana y marxista me parece enteramente pertinente, como por otra parte luego esencial del conjunto de la formulación de Marx, para pensar a la clase trabajadora hoy (Antunes, R. 2005, p. 190).
Otros autores perciben también las mutaciones ocurridas en la estructura de clases de las sociedades del siglo XX. Así, afirmando la centralidad del trabajo y captando las tendencias contemporáneas, sobre todo en Europa, Luciano Vasapollo ve el paso del fordismo al posfordismo como la conversión de lo que él llama "trabajo atípico" en "trabajo típico”, y que se desarrolla en actividades como la agricultura, el turismo, las telecomunicaciones, los transportes, entre otras: "Desde el punto de vista de los trabajadores, la informatización, más allá de provocar desempleo estructural, descalificó el trabajo existente, convirtiendo en 'típico' el trabajo atípico altamente precario". ${ }^{11}$

Por su parte, Sadi Dal Rasso, captando los cambios introducidos por la revolución informática, habla de la "clase de los trabajadores inmateriales intensificados", enfatizando la intensificación del trabajo introducida por la moderna organización del proceso de trabajo en el mundo y por sus métodos productivos, como el toyotismo (Dal Rosso, 2008).

Estas denominaciones conceptuales reflejan los cambios operados en el último medio siglo tanto en la estructura de clases del capitalismo mundial como en la estructura particular de la clase obrera y, en general, de las clases explotadas y oprimidas de la sociedad: el proletariado ampliado por la incursión a sus filas de extensos sectores de la población oprimida y explotada por el capital y el Estado.

Recebido para publicação em 16 de agosto de 2013 Aceito em 17 de novembro de 2013

${ }^{11}$ Vasapollo, L. (2007, p.77). Si por precariedad entendemos también informalidad, en el caso de México, por ejemplo, según cifras del Panorama del empleo 2008 de la ocde, $60 \%$ de la pea de este país actualmente está integrada en la informalidad. Véase: EL DESEMPLEO sigue en ascenso este año en países ricos: ocde”, La Jornada: en http://www.jornada.unam.mx/2008/07/03/index. php?section=economia\&article $=023 n 1$ eco, 3 jul. 2008. 


\section{REFERÊNCIAS}

ALVES, Giovanni. A condição da proletariedade. Londrina: Práxis, 2009.

. Dimensões da reestruturação produtiva. Ensaios de sociologia do trabalho, Londrina: Práxis, 2007.

Trabalho e subjetividade. O espírito do toyotismo na era do capitalismo manipulatório. Sao Paulo: Boitempo, 2011.

Crise estrutural do capital: trabalho imaterial e modelo de competência, notas dialéticas. In: CORSI, Francisco Luiz et al. (Org.) Trabalho e educação. Contradições do capitalismo global. Londrina: Práxis, 2006. p.47-81.

AMORIM, Henrique. Trabalho imaterial. Marx e o debate contemporâneo. São Paulo: FAPESP-Annablume Editora, 2009.

ALTHUSSER, Louis. La revolución teórica de Marx. México: Siglo XXI, 1976.

ANTUNES, Ricardo; BRAGA, Ruy. Infoproletários. Degradação real do trabalho virtual. São Paulo: Boitempo Editorial, 2009.

ANTUNES, Ricardo . Los sentidos del trabajo. Buenos Aires: Ediciones Herramienta, 2005.

BIHR, Alain. Las formas concretas del trabajo abstracto Revista Herramienta, Buenos Aires, n.44, p.29-37, jun. 2010.

CORSI, Francisco Luiz et al. (Org.) Trabalho e educação. Contradições do capitalismo global. São Paulo: Editora Práxis, 2006. p.70.

CUEVA, Agustín. La teoría marxista. Categorías de base y problemas actuales. Quito: Editorial Planeta, 1987.

DAL ROSSO, Sadi. Mais trabalho. A intensificação do trabalho na sociedade contemporânea. São Paulo: Boitempo Editorial, 2008.

EL DESEMPLEO sigue en ascenso este año en países ricos: ocDE. La Jornada 03 jul. 2008. Disponível em: http:/ /www.jornada.unam.mx/2008/07/03/index.php?section= economia\& article $=023 \mathrm{n} 1 \mathrm{ec}$

FIGUEROA CORNEJO, Andrés. Reflexión acerca de las luchas de los trabajadores bancarios contra la flexibilidad laboral. Rebelión. Disponível em: http://www.rebelion.org/ noticia.php?id=56948. Acesso em: 20 sep. 2007

GURVITCH. Georges. El concepto de clases sociales desde Marx a nuestros días. Buenos Aires: Nueva Visión 1973.

A UNIÓN Europea acuerda ampliar la jornada labora hasta un máximo de 65 horas semanales. Rebelión, 10 jun. 2008. http://www.rebelion.org/noticia.php?id=68646

LAURIN-FRENETTE, Nicole. Las teorías funcionalistas de las clases sociales, sociología e ideología burguesa. 2.ed. Madrid: Siglo XXI, 1985.

LENIN, V.I. Una gran iniciativa. OE. Moscú: Editorial Progreso, 1971.
MARINI, Ruy Mauro. Las razones del neodesarrollismo. (Respuesta a Fernando Enrique Cardoso y José Serra). Revista Mexicana de Sociología, Mexico, IIS-UNAM, v. 40, n.extraordinario, p.57-106, 1978.

Proceso y tendencias de la globalización capitalista. In: MARINI, Ruy Mauro; MILLÁN, Márgara. La teoría social latinoamericana. Mexico: Ediciones El Caballito, 1996. v.4 (Cuestiones contemporáneas).

MARINI, Ruy Mauro. Proceso y tendencias de la globalización capitalista. Disponível em: http:// biblioteca.clacso.edu.ar/ar/libros/secret/critico/marini/ 08proceso.pdf.

MARX, Karl. El 18 Brumario de Luis Bonaparte, OE. Moscú: Editorial Progreso, s/f.

p.188.

El capital. Livro I, México: FCE, 1980. v. I., cap.I,

El capital, Livro I, cap.VIII, México: FCE, 2000.p.

- Capítulo VI (Inédito). Resultados del proceso inmediato de producción. México: Siglo XXI, 1981.

MARX, Karl.; ENGELS, Federico. Manifiesto del Partido Comunista. Moscú: OE, Editorial Progreso, s.f.

MARX, Karl. Elementos fundamentales para la crítica de la economía política (Grundrisse) 1857-1858, Livro I. México: Siglo XXI, 1980. p.283-284.

MÉSZÁROS, István. El siglo XX: ¿Socialismo o barbarie? Buenos Aires: Ediciones Herramienta, 2003.

Más allá del capital, hacia una teoría de la transición. Caracas: Vadell Hermanos Editories, 2001.

NEGRI, Antonio. Marx más allá de Marx. Madrid: Editorial Akal, 2001.

OSSOWSKY, Stanislav. Estructura de clase y conciencia social. Barcelona: Península, 1969.

POULANTZAS, Nicos, Las clases sociales en el capitalismo actual. México: Siglo XXI, 1978.

Poder político y clases sociales en el Estado capitalista. México: Siglo XXI, 1971.

REICH, Robert. El trabajo de las naciones. Hacia el capitalismo del siglo XXI. Buenos Aires: Javier Vergara Editor, 1993.

RECHAZÓ el Parlamento Europeo proyecto de ley para aumentar la jornada laboral. La Jornada 18.dic. 2008. http: /www.jornada.unam. $m x / 2008 / 12 / 18 /$ index.php? section $=$ economia\&article $=029$ n 1 eco. 18 dic. 2008.

SOTELO VALENCIA, Adrián, Crisis capitalista y desmedida del valor: un enfoque desde los Grundrisse, México: Editorial Itaca;UNAM-FCPYS, 2010.

Los rumbos del trabajo. Superexplotación y precariedad social en el Siglo XXI. México: Editorial Miguel Ángel Porrúa;FCPyS-UNAM, 2012.

TREJO, Rubén, Despojo capitalista y privatización México, 1982-2010. México: Editorial ITACA, 2012. p. 337.

VASAPOLLO, Luciano. O devir posfordista e o traballo atípico como elemento estratégico. In: MARTUFI, Rita VASAPOLLO, Luciano. O mundo do traballo fronte á globalización capitalista. Galiza,Es: CIGa, 2007. 


\section{IMMATERIAL LABOR IN THE MATERIAL CYCLE OF CAPITAL AND THE INFLUENCE OF SOCIAL CLASSES ON CONTEMPORARY CAPITALISM}

\section{Adrián Sotelo Valencia}

This paper aims to establish a dialectical connection between the concept of immaterial labor and the cycle of material labor in the production and reproduction of capital and in bourgeois society. In the same way, its purpose is to consider some hypotheses related to the way that immaterial labor affects the shaping of social classes - and their struggle - in contemporary capitalist society.

KEY wORDS: Immaterial labor. Class and Social Struggle. Value. Capitalism.

\section{LE TRAVAIL IMMATÉRIEL DANS LE CYCLE MATÉRIEL DU CAPITAL ET LA DÉTERMINATION DES CLASSES SOCIALES DANS LE CAPITALISME CONTEMPORAIN}

\section{Adrián Sotelo Valencia}

Dans cet article, nous essayons d'établir un lien dialectique entre le concept du travail immatériel et le cycle du travail matériel dans la production et la reproduction du capital et de la société bourgeoise. Nous y faisons aussi une réflexion concernant certaines hypothèses quant à la façon dont le travail immatériel a une incidence sur la formation des classes sociales - et dans leurs luttes - dans la société capitaliste contemporaine.

Mots-CLÉs: Travail immatériel. Classes et luttes sociales. Valeur. Capitalisme.

Adrián Sotelo Valencia - Doutor em Estudios Latinoamericanos. Professor e investigador do Centro de Estudios Latinoamericanos (CELA) da FCPyS - UNAM. Coordenador do Programa Constitución Estructural de AL, UNAM. Integra o Núcleo de Pesquisa Teoría de la dependencia, desenvolvendo pesquisas na área de Dependencia y desarrollo de AL. Suas mais recentes publicações, são: A reestruturação do mundo do trabalho. Superexploração e novos paradigmas de organização do trabalho. Editora da Universidade Federal de Uberlândia, Minas Gerais, Brasil. 2009; Crisis capitalista y desmedida del valor: un enfoque desde los Grundrisse, coedición Editorial ITACA-UNAM-FCPyS, México, 2010; Los rumbos del trabajo. Superexplotación y precariedad social em el Siglo XXI, coedición Miguel Ángel Porrúa - FCPyS, México, 2012. 